\title{
A Study of Using M-Learning Approach to Enrich English Language Teaching: With Special Reference to G.C.E. Advanced Level Students in Kalutara Education Zone
}

Sri Lanka Journal of Social Sciences and Humanities Volume 1 Issue 2, August 2021: 175-179 ISSN: 2773 692X (Online), 27736911 (Print) Copyright: (C) 2021 The Author(s)

Published by Faculty of Social Sciences and Languages, Sabaragamuwa University of Sri Lanka Website: https://www.sab.ac.lk/sljssh DOI: http://doi.org/10.4038/sljssh.v1i2.48

\author{
Silva, N.A.L.D.R. ${ }^{1,{ }^{*}}$ and Alahakoon, A.M.Y.S. ${ }^{2}$ \\ ${ }^{1}$ Department of English Language Teaching, Sabaragamuwa University of Sri Lanka, Belihuloya, 70140, Sri Lanka. \\ 2 Department of English Language Teaching, Uva Wellassa of Sri Lanka, Badulla, 90000, Sri Lanka.
}

Received: 30 November, 2020, Revised: 09 April, 2021, Accepted: 27 June, 2021.

How to Cite this Article: Silva, N.A.L.D.R. and Alahakoon, A.M.Y.S.A. (2021). Study of using M-Learning approach to enrich English language teaching: With special peference to G.C.E. advanced level students in the Kalutara education zone. Sri Lanka Journal of Social Sciences and Humanities, 1(2), 175-179.

\begin{abstract}
Mobile-Assisted Language Learning (MALL) - a topic of current interest - is a subset of the approach, Computer- Assisted Language Learning (CALL), deals with handheld mobile devices making the learning process more personalized, spontaneous and ubiquitous. The students learning in the secondary level, find a lot of difficulties when integrating mobile phones in the language learning process. In this study, the main objective is to investigate the perspective of the G.C.E. A/L students towards MALL. A sample of fifty students were selected from the Kalutara Education Zone by using convenient sampling method and the data collected through a Google questionnaire, were analyzed both qualitatively and quantitatively. The analysis confirmed that the majority of the respondents do have a positive attitude towards the use of MALL approach as a mean of distance learning. The results of the study portray the abundance of benefits of using $\mathrm{m}$ - learning in the secondary education, such as easy and quick access and availability of a plenty of resources and etc. In view of the difficulties encountered when using $\mathrm{m}$ - learning approach, the data manifested the commonness of difficulties encountered by ESL learners in the categories of: connection problems, monetary issues, lack of high- tech sophisticated devices and lack of feedback. Although the findings convince that the students choose blended learning system, MALL would be more preferred if the basic requirements such as a proper training and knowledge are provided.
\end{abstract}

Keywords: English as a Second Language, Mobile Assisted Language Learning

\section{INTRODUCTION}

The COVID-19 pandemic has created the largest disruption of education systems in history, affecting nearly 1.6 billion learners in more than 190 countries and all continents. Closures of schools and other learning spaces have impacted $94 \%$ of the world's student population, up to $99 \%$ in low and lower-middle income countries (United Nations, 2020). With the outbreak of COVID -19, the situation of education system of Sri Lanka was affected in many ways. Being a country of lower-middle income, in Sri Lankan pedagogical system, using technology at large in education is not effusively feasible. Moreover, pre-existing education discrepancies were worsened due to the lack of resources for many of the weakest learners in poor or rural areas to continue their learning. Despite all these complications, teachers of all the educational institutions (primary, secondary and tertiary) are requested to conduct the classes virtually since that has become the most possible alternative. This has forced the universities to introduce courses through online portals. Also, digital video conferencing platforms like Zoom, Microsoft platform, and Webex Blackboard and Google Classroom (Larry 2020) are highly demanding. Therefore, this will be enhancing electronic- learning (e-learning), globally (Chen
2010; Yengin et al. 2011; Larry 2020). On the contrary, in Sri Lanka, for primary and secondary education, WhatsApp and Zoom are the primarily used platforms for e- learning. Hence, MALL is more popular in comparison to CALL.

Throughout the history, the school education system in Sri Lanka was majorly based on the traditional formal education system. In 2020, the COVID- 19 pandemic situation affected the global economy. Consequently, the education system was also challenged. Thus, virtual classrooms have become more popular and it has resulted in using Computer Assisted Learning system and Mobile Assisted Learning systems as possibilities for teaching purposes.

The current pandemic situation occurred in Sri Lanka was taken into consideration when conducting this study. Although online teaching has become the most possible and suitable option to continue the teaching- learning process, there are a lot of difficulties faced by the language learners when using mobile phones for their study purposes. Thus, in this research the primary attention was paid on finding the opinion of G.C.E. A/L students on m-learning. As well, in the survey, attempts are made to investigate the advantages, disadvantages and difficulties faced by the students when

\footnotetext{
* Corresponding author: Tel.: +94 (71) 916 2752; Email: dilusha@ssl.sab.ac.lk (iD) https://orcid.org/0000-0002-6082-2394
} 
using $\mathrm{m}$ - learning approach. In this respect, the study was conducted based on the data collected from the children of state schools in Kalutara Education Zone.

In this study, the researcher has hypothesized that the students who are doing G.E.C. A/Ls use mobile phones for study purposes in order to answer the following research question;

What are the perspectives of $A / L$ students towards Mobile Assisted Language Learning Approach?

\section{LITERATURE REVIEW}

\section{E-learning}

Today E-learning is getting very popular worldwide. E-learning is described as the delivery of learning through technology and the internet (Gros et al. 2016; Hong et al. 2017; Aljawarneh 2020).

Nearly all the education institutes, worldwide, have developed the e-learning platforms for their students. In the world, today, e- learning has created an irresistible impact on the students who are from different educational backgrounds such as part- time language learners, full- time language learners as well as more importantly, distance learning students.

\section{M- learning}

Mobile learning is considered part of e-learning as well as distance learning. By using m-learning, facilitators may motivate the students to learn from inside and outside the classroom (Hamdani, 2013).

There is a difference between e-learning and m-learning. Usually, E-learning is the process of learning without participating in the classroom (Rosenberg, 2001). Sharples (2005) illustrates that m-learning is the extension of e-learning (Sharples, 2005). M-learning can be defined as acquisition of any knowledge and skills through the use of mobile technology, anywhere and anytime (Hashemi, Azizinezhad, Najafi, \& Nesari, 2011).

$\mathrm{M}$ - learning is occurred with the intermediation of content or collaborations facilitated by mobile devices such as mobile phones, mp3 players, tablets, desktop computers, laptops, data storage devices and a lot of other handy devices. Until today, the concept, M-learning has not been defined clearly. Yet, the researchers agree that m-learning should not be considered a mere learning process with the intermediation of a mobile device.

Furthermore, it can be identified as a learning process which has been facilitated by handheld, wearable and portable devices. It further supports the students to learn not only in physical language learning contexts, but also in virtual platforms.

In the current world, the number of smartphone users is around 3.5 billion, and this means $45.15 \%$ of the world's population owns a smartphone. According to the statistics, in the year 2018, 24.43 million out of the population of 21 million have subscribed for mobile phones in Sri Lanka. Therefore, in many ways, mobile learning can be considered the new generation of e-learning in a world of digitally native learners.

The researches on mobile learning are extensive due to the rapid enhancement of technology. As a result, the findings become outdated very quickly. MALL- a topic of current interest - is a subset of the approach, CALL, deals with handheld mobile devices making the learning process more personalized, spontaneous and ubiquitous (Miangah and Nezarat, 2012).
Various researches identified that mobile learning ( $m$ - learning) is capable of supporting more innovative constructivist, collaborative, learner-centered instruction, in contrast to the teacher-led classroom pedagogical situations. MobileAssisted Language Learning, a successor of Computer-Assisted Language Learning, is a new phase in the learning of second and foreign language.

The mobile device is now a common device which is used at all aspects of life in both developed and developing countries. It has many advantages. M- learning, being ubiquitous, supports the method of teaching could take place at any place, anytime and the process of learning is not limited to a specific place (Corbeil \& Valdes-Corbeil, 2007). It assists the students to improve technological skills, to help of sharing knowledge, and also develop their learning capability (AlEmran, Elsherif, \& Shaalan, 2016).

Quinn (2000) defined m-learning as a new learning technique by using mobile devices. Furthermore, Kinash et al. (2012) stated that m-learning is useful for educational purposes. Mobile learning plays a significant role in education in both teaching and learning (Klassen et al., 2013).

Nassuora (2013) conducted another study to examine students' acceptance of mobile learning in Saudi Arabia. The author had found that m-learning acceptance of Saudi Arabia is high at the higher studies level by executing a questionnaire survey among 80 students (Nassuora, 2013). In another study on mobile phone usage and potential for $\mathrm{m}$ learning based on Panama by Valderrama Bahamóndez and Scmidt (2010) it is revealed that mobile phone usages among school children are going high and teacher and students all accept using their mobile phone for the purpose of learning. Chinese universities and colleges also used mobile as a learning and teaching tool that is supported by the government as well as university administration.

Mobile learning is potentially the most exciting, innovative, and technologically advanced system that will help the effect of revolutionizing the delivery of the higher education institution in the future. It is regarded as a unique tool in various settings of the educational institutions (Ahmad, 2019).

Kloper et al. (2002) claimed five properties of mobile devices which can produce unique educational affordances such as portability i.e. such devices can be taken to different places due to small size and weight, social interactivity i.e. exchanging data and collaboration with other learners is possible through mobile devices, context sensitivity i.e. the data on the mobile devices can be gathered and responded uniquely to the current location and time, connectivity i.e. mobile devices can be connected to other devices, data collection devices, or a common network by creating a shared network, individuality i.e. activity platforms can be customized for individual learner.

\section{M- learning during COVID pandemic}

The potential of MALL is enormous and by studying this field, it is possible to learn how to make the most out of it since it suits well in resource poor environments also. Today, mobile-learning has become a widespread learning system for education especially in higher education all over the world because of its multi-functionality features and effectiveness. M-learning reflects remote teaching tactics for teachers as well as learning strategies for students at school level because it helps to learn anytime from anywhere. Moreover, it might aid the students to condense the study gap and act as a substitute for learning during COVID-19 pandemic period (Naciri et al., 2020). 
After declaring COVID-19 as a pandemic disease, many countries including Sri Lanka have taken initiatives to close their educational institutions to reduce the effect of the virus (World Health Organization, 2020). So, for overcoming this situation, an innovative learning methodology has become very important nowadays (Toquero, 2020) and mlearning could play a vital role for the mobile devices used in the education sector (Sönmez, Göçmez, Uygun, Ataizi, \& 2018, Aubusson, Schuck, \& Burden, 2009). For the COVID-19 period, the education system of the world has extremely been affected. Many countries of the world have closed their educational institutions to reduce the spread of this virus which has become the cause of many challenges (Naciri et al., 2020).

Mobile learning which can be recognized as a blended, private, interactive, collaborative, and instant process of language learning, is considered portable because a learner can use it anytime, anywhere (Cavus \& Ibrahim, 2009). It is universal as it changes the classroom setting from the traditional to virtual (Cavus \& Ibrahim, 2009; Kukulska Hulme et al., 2009).

Moreover it can ensure the face-to-face and easy access to online interaction (Ocak, 2010); interactive in which it can provide an interactive learning environment (Cavus \& Uzunboylu, 2009); collaborative because it creates collaborative learning activities (Uzunboylu et al., 2009); immediate as it allows instant access to learning materials and educational instruction (Eteokleous \& Ktoridou, 2009).

Furthermore, mobile platforms can be perceived as very effective since the learners are allowed to collaborate with their classmates, search information, find and search locations" (Chen et al., 2013) Nowadays, mobile phones are cheaper than other devices like desktop computers or laptops, and hence, it is claimed that mobile phones are suitable as learning devices for the students at a low cost (Dawson, 2007; Haug \& Tumbo 2016).

\section{METHODOLOGY}

Having observed the virtual classrooms on both quantitative and qualitative basis as the baseline of the study, a survey was carried out through a questionnaire to ascertain data for the study. Methods of sampling, data sources, procedure, the tools of the study and the analysis methods relevant are briefed below.

A limited sample was used in collecting data due to time and resource constraints. The respondents, chosen should possess rich information of the subject matter being studied and be ready to open up to share their experiences during the process of data collection. The population consists of the students who are doing G.C.E. Advanced Level examination in the year of 2021 and studying at government schools in Kalutara Education Zone. The sample consists of fifty (50) grade 13 G.C.E. A/L students in state schools in Kalutara Education Zone irrespective of their gender and the subject streams (arts, commerce, technology, science or mathematics) they follow. The sample was selected using convenience sampling technique.

The study will be mostly qualitative as much of the information remains observations of the researchers while a survey of questionnaire too involves in. In order to investigate the perspective of G.C.E. A/L students on using $m$ - learning approach, a questionnaire survey which is a descriptive correlational method, was used as the primary method of data collection. The method was selected as it is more suitable to analyze the current situation based to the study. Questionnaires delivered through Google were identified as the most effective and efficient way to collect data due to the prevailing situation of Sri Lanka. As the secondary sources of data collection, books, journals and scholarly articles were used.

In the study, questionnaires were used and the method is considered more useful instrument implemented in humanities and social sciences. Questionnaires have been designed in both Sinhala and English media for G.C.E. A/L students in order to achieve more reliable data. Based on these tools, attempts have been made to investigate the perception of G.C.E. A/L students on MALL.

\section{DISCUSSION OF THE FINDINGS}

In this study, an overall content analysis of the data, collected through the questionnaire survey is done using both qualitative and quantitative methods of analyzing data. Ascertaining the usage of mobile phones in learning process by the G.C.E. Advanced Level students remains the objective of this questionnaire.

The data obtained from fifty G.C.E. A/L students depicts that a vast z percentage of 89 of the sample, use mobile phones every day for study purposes. Having $8 \%$ of the students often using mobile phones, only one student has mentioned that the mobile phone is rarely used for the study purposes. Therefore, the study depicts that a massive majority which obtained a percentage of 97 of the students do use mobile phones to learn English language.

The second statement which is about the time or the number of hours spent on using mobile phones to learn English as a Second language yields the following observations. A majority of the students which is a percentage of 67 spend 2-3 hours for language learning. A minority of $34 \%$ of the students spend about 1-2 hours to learn English language during the COVID - 19 period.

The data relevant to the third statement show that $52 \%$ of the $A / L$ students anticipate that completely depending on the mobile phone to learn a second language is not much effective while a minority of the sample thinks that integration of mobile phones in language learning has a positive effect on the improvement of the second language. It shows a percentage of $47 \%$ according to the study.

On the contrary, the fourth question of the questionnaire is to estimate whether $\mathrm{m}$ - learning is supportive for distance learning during this difficult period. In this regard, the opinion of the students is completely contradictory. Because $82 \%$ of the students, out of 50 participants think that mlearning is an extremely important approach to sustain distance learning. Furthermore, the informal discussions with the students implied that they are well aware of the importance of having the m-learning platform during this pandemic time.

The data of the first episode of the questionnaire manifest that the majority of the students have a positive opinion towards the approach of Mobile Assisted Language Learning during this difficult period since $\mathrm{m}$ - learning is supportive as well as productive as an alternative for distance learning. At the same time, they agree that the lack of exposure to these technology integrated learning system has affected negatively when it comes to full time learning.

In order to facilitate data analyzing process, answers given by the teachers for the fifth statement which was about the difficulties faced by the students when using mobile assisted 
language learning approach, were classified under seven main criteria. The difficulties noted by the teachers were categorized as connection problems, problems in comprehension and lack of teacher intervention, monetary issues, technical issues, distractive nature, lack of feedback and lack of sophisticated phones. Only a percentage of 8 of the students have found no difficulties in using mobile assisted approach for language learning.

Considering the sample, $46 \%$ of the students find it difficult to use mobile phones for study purposes due to inadequate network connection. In some of the rural areas of Kalutara district, the network connection is very poor and it results in having low signal strength. Students further elucidate that as a consequence, it affects the effectiveness of using mobile phones in studying the second language.

Moreover, a percentage of 28 students illuminate that it is very difficult to understand the content, especially theory parts, when they learn a lesson using mobile phones. For years, they used to learn a language in a formal face- to- face classroom setting and the sudden change occurred due to the COVID- 19 pandemic situation, the students had to adopt to a technology intermediated learning environment. Thus, the students elaborated that lack of proper training in this regard, matters a lot when they use mobile assisted technology for second language learning.

A percentage of 20 out of the sample stated that monetary issues have become an adversity in using mobile phones for learning a language. The students who do not have $\mathrm{Wi}-\mathrm{Fi}$ connection, spend a lot of money to use mobile data when accessing internet since most of the sites are not for free access.

An equal number of students, which is a $14 \%$ out of 50 students have found a lot of technical issues when using technology integrated language learning approach. $A / L$ students who do not have a good knowledge on Information Technology (IT) except the students who have done IT as a subject and followed courses in IT, cannot manage and solve the technical issues they encounter during the lessons.

The responses show that $12 \%$ of the students believe that the distractive nature of mobile phones is a great difficulty they encounter when using $\mathrm{m}$ - learning approach. As per their explanation, when they study using the mobile phones, the get distracted easily. For instance, when they get notifications from social media or messages from the friends, it is difficult to concentrate on the learning process.

The data collected shows that an equal number $(10 \%)$ of the students identify the lack of feedback from a teacher and not having sophisticated mobile phones as two major difficulties they face when using $\mathrm{m}$ - learning approach.

The sixth question of the questionnaire is on the benefits of using mobile phones to learn English language. The answers given by the students are classified as development of vocabulary, abundance of resources, easy access, easy to comprehend, time saving, improving language skills, and ubiquity. Only a percentage of 10 of the students have stated that they have no specific idea with regarding this statement.

A majority of the students thinks that the $\mathrm{m}$ - learning approach is useful in terms of developing the vocabulary. They further elaborate it as they acquire a great opportunity to get exposed to the practical situations to use English language. As well, their answers contained a variety of ideas such as developing learner autonomy since it helps them to find new knowledge independently and use it in practical sit- uations. They further elaborate the fact stating that the introverted students are given a great opportunity to work according to their preference. The students suppose that the mobile integrated learning is very useful since it helps them to improve 21 st century skills which are very significant aspects a learner should have developed.

The second most common benefit identified by the students is the abundance of resources they can find on internet. According to the results of the survey, a percentage of 22 of the participants have viewed $\mathrm{m}$ - learning as advantageous since the resources available on internet are ample and very productive.

Moreover, $14 \%$ of the sample thinks that they can easily access the resources via the mobile phones. They further describe the fact as the mobile phones are more productive in many ways than computer/ laptop integrated language learning. At the same time, an equal number of students find $\mathrm{m}$ - learning a more comprehensive approach for learning English language.

An equal percentage $(10 \%)$ of the students states that the intervention of mobile phones in the language learning process is very efficient and effective since it saves the time of the learners and the ubiquity of it is very helpful for the learners in secondary level to learn the language according to their phase and convenience.

Finally, a minority of the students perceive that they can improve all four language skills by using mobile phones when they study English language. It is a $6 \%$ of the sample of 50 students.

The seventh question addresses the disadvantages of using mobile phones in the process of second language learning. The frequency of answers obtained through the Google form can be used to categorize the disadvantages of extending mlearning approach in language learning process as lack of experience in teacher- learner traditional encounter, decaying of writing skills, especially spellings, teacher centeredness and health issues. Only a few students that represent a percentage of 12 have declared that the $\mathrm{m}$ - learning process is not disadvantageous at all.

A majority of students (30\%) perceive that $\mathrm{m}$ - learning is not much effective since they could learn a lot of things in traditional classrooms where learner- teacher relationship is very strong. The answers manifest that students accept that they can gain knowledge but they lack the attitudinal aspect which is very important in the teaching learning process. Hence, they state that this approach is disadvantageous.

A percentage of 15 students state that when they get used to mobile phones when learning the second language, they pay less attention on improving their writing skills. They specify that they lose the concentration on spellings which is considerably an important aspect in the learning process since the mobile phone corrects the spelling mistakes automatically.

A minority of the students have explained that using mobile phones continuously for long hours affect their health condition. Especially the students who have poor eye sight find it more difficult to look at the small screens of their mobile phones ceaselessly. The numerical depiction of the students who have encountered health complications due to $\mathrm{m}$ learning is a percentage of 11 .

The last question of the questionnaire was designed in order to gain the students' opinion regarding the most effective methods of second language learning in accordance with their experience. The students were given three options to choose their preference as traditional classroom learning, 
Mobile Assisted Language Learning and blended learning. A vast majority (78\%) of the students prefer blended learning approach while $22 \%$ of the respondents prefer the classroom based education system.

The results of the study illustrated a lot of important factors as well as aspects that can be incorporated for the advancement of the field of English Language Teaching. Most influentially, the results depicted that none of the students prefer to use Mobile Assisted Language Learning approach, exclusively for second language learning. The informal conversations conducted with the students highlighted that although they are well aware of the advantages and the positive aspects of the MALL as an approach to learn the second language, the difficulties they encounter hinder their preference to choose $\mathrm{m}$ - learning totally. Instead, these students who are in the secondary education level would prefer to amalgamate the traditional classroom setting with mobile learning approach to enhance the value of the pedagogical system and they think that it will make a more effective language learning environment which will facilitate the teaching learning process massively.

\section{CONCLUSION}

Although the importance of practising e- learning was highlighted in the earlier researches, until the COVID - 19 outbreak, the importance of its practical implementation was not well understood. If the opportunity given by this pandemic situation is properly used, application of e- learning or $\mathrm{m}$ - learning would not be a difficulty anymore. To achieve it, a proper training and logistics are the basic requirements that should first be fulfilled. The study showed that the students have a positive perception on $\mathrm{m}$ - learning and they would like to embrace the $\mathrm{m}$ - learning system due to the incredible advantages of it. If the feasibility of providing facilities and training is assured, students would definitely like to use $\mathrm{m}$ - learning approach exclusively in order to learn the second language.

Furthermore, by identifying the challenges of implementing $\mathrm{m}$ - learning as an approach to teach English as a Second Language through this research, it is expected that the English language practitioners will be able to take necessary actions to overcome those difficulties and bring about the teaching process effectively. Additionally, the policy makers are also given a great chance to incorporate the online teaching approaches, specifically, MALL, in the future curricula and syllabuses. The findings implied that the students prefer the blended learning approach rather than being framed to a single approach. On the other hand, the blended learning method is emphasized in the field of ELT Thus, having a thorough knowledge on online teaching is obligatory in order to inculcate blended approach to second language teaching.

\section{REFERENCES}

D. Adams, B., Almarashdeh, I., Aljawarneh, S., F. Alvino, A., M. Aparicio, F., M. Aparicio, T., . . . I. Yengin, A. (1970, January 01). Effects of COVID-19 in E-learning on higher education institution students: The group comparison between male and female. Retrieved November 29, 2020, from https://link.springer.com/article/10.1007/s11135020-01028-z

Fadda, H. A., \& Qasim, N. A. (2013). From Call to Mall: The Effectiveness of Podcast on EFL Higher Education Students' Listening Comprehension. English Language Teaching, 6(9). doi:10.5539/elt.v6n9p30

Miangah, T. M. (2012). Mobile-Assisted Language Learning. International Journal of Distributed and Parallel Systems, 3(1), 309-319. doi:10.5121/ijdps.2012.3126
Mosavi Miangah, Tayebeh \& Nezarat, Amin. (2012). Mobile-Assisted Language Learning. International Journal of Distributed and Parallel Systems. 3. 309-319.. 10.5121/ijdps.2012.3126.

UNSDG | Policy Brief: Education during COVID-19 and beyond. (n.d.). Retrieved November 29, 2020, from https://unsdg.un.org/resources/policy-brief-education-during-covid-19-and-beyond

Zimmermann@stlouisfed.org, \& Luis Espino-Díaz \& Gemma FernandezCaminero \& Carmen-Maria Hernandez-Lloret \& Hugo Gonzalez-Gonzalez \& Jose-Luis Alvarez-Castillo. (1970, January 01). Analyzing the Impact of COVID-19 on Education Professionals. Toward a Paradigm Shift: ICT and Neuroeducation as a Binomial of Action, by Luis EspinoDíaz; Gemma Fernandez-Caminero; Carmen-Maria Hernandez-Lloret; Hugo Gonzalez-Gonzalez; Jose-Luis Alvarez-Castillo. Retrieved November 29, 2020, from https://ideas.repec.org/a/gam/jsusta/v12y2020i14p5646d384169.html 
